\title{
Anhang III: Kurzfragebogen
}

Studie: (Aus)Sicht medizinischer Akteure auf die stationare Versorgung schwerstkranker und sterbender Menschen im Krankenhaus

\section{Demografische Angaben - Kurzfragebogen}

Datum des Interviews:

(ID:_---)

Ort des Interviews:

Geschlecht:

Weiblich

Mănnlich

Anderes

Alter:

Staatsbürgerschaft:

Migrationshintergrund

nein

ja

Eigene Migrationserfahrung:

Religion:

Praktizierend: ja $\square \quad$ nein $\square$

Ausbildung/akademischer Abschluss:

$\rightarrow$ Abschluss seit:

Medizinische Fachdisziplin:

Zusätzliche Qualifikationen (was / seit wann):

Seit wann in dieser Klink beschäftigt:

Teilzeit

mit Stunden/Monat

Seit wann im gegenwărtigen Arbeitsbereich beschăftigt:

Aktuelle Position im Arbeitsbereich:

Seit wann in der aktuellen Position:

Zusätzliche Arbeitsbereiche:

Klinische Erfahrungen in einem anderen Krankenhaus:

ja $\square \quad$ nein $\square$

Studienleitung: Dipl.-Psych. Asita Behzadi

Stand: 06.2013

○ Open Access. (C) 2020 Asita Behzadi, publiziert von De Gruyter. (cc) BY-NC-ND Dieses Werk ist lizenziert unter der Creative Commons Attribution-NonCommercial-NoDerivatives 4.0 Lizenz. https://doi.org/10.1515/9783110707151-011 
